\title{
Dynamic bottleneck elimination in mattress manufacturing line using theory of constraints
}

\author{
Emin Gundogar, Murat Sari ${ }^{*}$ and Abdullah H. Kokcam
}

\author{
*Correspondence: \\ muratsari@sakarya.edu.tr \\ Industrial Engineering \\ Department, Sakarya \\ University, 54187 Sakarya, \\ Turkey
}

\begin{abstract}
There is a tough competition in the furniture sector like other sectors. Along with the varying product range, production system should also be renewed on a regular basis and the production costs should be kept under control. In this study, spring mattress manufacturing line of a furniture manufacturing company is analyzed. The company wants to increase its production output with new investments. The objective is to find the bottlenecks in production line in order to balance the semi-finished material flow. These bottlenecks are investigated and several different scenarios are tested to improve the current manufacturing system. The problem with a main theme based on the elimination of the bottleneck is solved using Goldratt and Cox's theory of constraints with a simulation based heuristic method. Near optimal alternatives are determined by system models built in Arena 13.5 simulation software. Results show that approximately $46 \%$ capacity enhancements with 2 buffer stocks have increased average production by $88.8 \%$.
\end{abstract}

Keywords: Bottleneck search, Buffer stock, Theory of constraints, Simulation, Spring mattress manufacturing

\section{Background}

Each company establishes its production system (number of employees, machine capacities, buffer stocks) with the capacity to produce its product range with optimum cost. The existing production system fails to optimally respond to the product range that varies with rapidly changing fashion. Along with the modifications in the product range, the production system should also be renewed on a regular basis, keeping the production costs under control. This especially applies to the furniture sector, with its great impact on the daily lives of people. Primarily, diversities in the product range pose several impediments for product standardization in the company analyzed in this study. The company uses an overtime manufacturing policy to address this problem leading to serious increases in the operational costs, which in turn urges them to find new ways to increase the production efficiency.

A congestion, encountered in any system from computer networks to a factory assembly line, is described with the term "bottleneck". In a system that is subject to a bottleneck, there is always a process, task, machine, etc. acting as the limiting factor for a

(c) 2016 The Author(s). This article is distributed under the terms of the Creative Commons Attribution 4.0 International License (http://creativecommons.org/licenses/by/4.0/), which permits unrestricted use, distribution, and reproduction in any medium, provided you give appropriate credit to the original author(s) and the source, provide a link to the Creative Commons license, and indicate if changes were made. 
greater throughput, thus determining the capacity of the entire system. Knowing about the bottleneck allows increasing the flow through improvement of a single process without having to intervene the whole system. In other words, the amendments made on any point other than the bottleneck, will not contribute to the output (Goldratt and Cox's 1984).

Production lines involve various parameters such as processing times and setup times, which render keeping the balance of the line a serious challenge. As suggested by Van Delft et al. (2008) solution of such problems by means of mathematical modelling and similar deterministic methods in polynomial time is not possible due to their complexity and stochastic nature instead heuristic and approximate methods can be used for this type of problems. Goldratt and Cox's (1992) TOC is one of the heuristic methods which can be easily implemented to a simulation environment. Therefore, the problem, main theme of which is based on the elimination of the bottlenecks, is solved using TOC by means of a simulation based heuristic method. TOC has been used in various topics such as health care, finance, production, operations management, and quality management (Mabin and Balderstone 2003; Orouji 2016). There are several theoretical works that used TOC on operations management (Boyd and Gupta 2004; Gupta and Boyd 2008), production process efficiency (Andelkovic et al. 2013), supply chain management (Puche et al. 2016).

Bottleneck elimination process has four main steps which should be investigated thoroughly. These are material, machine and man (workforce), respectively (Üstün 2005). Bottleneck detection and elimination methods have been studied since the industrial revolution, since detection of a bottleneck in a production system is a complex task. In the literature, there have been numerous studies about current bottleneck detection methods which can be divided into two categories as analytical and simulation-based ( $\mathrm{Li}$ et al. 2007).

Analytical methods yield satisfactory and reasonable results for long term analyses but they are not suitable for short term analyses, since they can give misleading results in short time intervals. There are several works including both fictive (Balbo and Serazzi 1997; Amirghasemi and Zamani 2014) and experimental (Li et al. 2009) case studies, and different analytical methods have been applied such as queuing theory (Lawrence and Buss 1995) and Markov chain theory (Chiang et al. 2001), for elimination of bottlenecks.

Analytical approaches are not as sufficiently applicable as simulation based methods for real manufacturing processes due to highly complicated dynamic/stochastic structure of the problem. On the other hand, simulation based methods have some disadvantages such as the time required for modelling since different scenarios require different models.

Simulation based methods are widely used in many areas such as production policies (Al-Harkan and Hariga 2007), inventory model (Firoozi et al. 2013), scheduling (Baesler et al. 2015), maintenance (Razavi et al. 2015), assignment (Lam et al. 2014) problems and also used in bottleneck elimination problems as following.

Leporis and Králová (2010) applied several methods in simulation environment to detect bottlenecks in manufacturing processes and compared the advantages and constraints related to these methods. Scholz-Reiter et al. (2011) developed a systematic and comprehensive definition of dynamic bottlenecks of the production networks based on 
both the TOC and the bottleneck-oriented logistic analysis. Gopalakrishnan et al. (2014) investigated how a shifting priority strategy could be integrated into the scheduling of reactive maintenance. They applied the strategy in an automotive case-study, using simulation for decision support. They showed how to shift prioritization by tracking the momentary bottleneck of the system.

On the other hand, in recent years, researchers have developed new hybrid methods and techniques such as meta-heuristic algorithms with simulations (Volling and Spengler 2011).

There are several studies (Sari et al. 2013; 2014a; b) similar to this one using only capacity increase to overcome bottleneck elimination problem.

Simulation methods are widely applied to investigate and estimate bottleneck problems in a workflow. The aim of the current study is to improve the flow of products by reducing bottlenecks in production line using simulation tools. The company receives orders from a wide range of dealers and directly transports the products to sub-vendors. In the current case, the company produces an average of $200( \pm 5)$ products. The company aims to reduce the unit product costs as much as possible through maximization of its daily output with required capacity enhancements. This is a case study to increase the production, based on factual data that have been acquired from a factory by modelling discrete event simulation (DES) of the production line.

The rest of the study is organized as follows. Detailed analysis of the product and the production line is given in the second section. Work study and input analysis is given in the third section. Definition, methodology, and application areas of the "theory of constraints" are explained in fourth section. Conceptual simulation model and application of package program is given in the fifth section. Verification and validation of the system is given in sixth section. Finally, simulation results and conclusion are given in the seventh section.

\section{Manufacturing system description}

A furniture company produces different spring mattresses. To understand the problem of interest, the materials used in a classical spring mattress are summarized in Table 1 and shown in Fig. 1.

Spring mattress manufacturing line consists of eight work stations, namely Spring Knitting, Gluing, Fabric Quilting, Overlock, Upholstering, Sewing, Quality control and

\section{Table 1 Descriptions of materials used in spring mattress}

\begin{tabular}{|c|c|}
\hline Material name & Description \\
\hline Fabric & A woven cloth of organic or inorganic filaments \\
\hline Mattress frame & $\begin{array}{l}\text { Mattresses are constructed by knitting spiral springs, which are made of high carbon reinforced } \\
\text { steel fibre processed with heat treatment }\end{array}$ \\
\hline Buckram & $\begin{array}{l}\text { A coarse cloth made of linen or hemp, stiffened with size or glue, which is used in garments to } \\
\text { keep them in the desired form }\end{array}$ \\
\hline Felt & $\begin{array}{l}\text { Nonwoven fabric made by stratifying thin sheets of carded wool fibers, which is processed } \\
\text { under heat, moisture, and pressure to shrink and compress the fibers into a thick matted } \\
\text { cloth that will not ravel or fray. The felt uniformly distributes the weight on bed surface }\end{array}$ \\
\hline Foam rubber & Light and spongy rubber which is used as a padding material in the mattress \\
\hline Wadding & $\begin{array}{l}\text { Soft fibrous cotton or wool material which is used for stuffing (wad) between fabric and mat- } \\
\text { tress frame }\end{array}$ \\
\hline
\end{tabular}




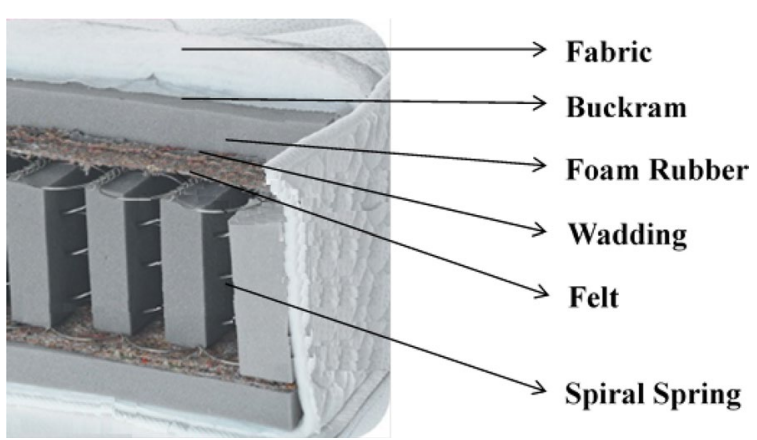

Fig. 1 The structure of classical spring mattress

Packaging. The mattress manufacturing process starts in two different lines. Mattress frame is built in the Spring Knitting station at the first line. Then appropriately sized felt and foam rubber are glued up to that mattress frame in the gluing station. The second branch of manufacturing line consists of Fabric Quilting and Overlock stations. Fabric, buckram, wadding and foam rubber are sewn with appropriate designs (pattern) according to the features of mattress being produced. Afterwards, quilted fabric is overlocked if necessary. After the completion of processes in these two lines, semi-finished products (mattress frame and quilted fabrics) are combined in Upholstering station. Top and bottom quilted fabrics and lateral fabric (called bordure) are combined with straight binding process in the sewing station. In the quality control station, scrap suture strands are removed from spring mattresses and physical examination test is carried out. Finally, the spring mattress is packaged automatically in the package station. Main steps of spring mattress manufacturing process are summarized in Fig. 2.

\section{Work study and input analysis}

As remarked by Law and Kelton (1991), a thorough and detailed modeling of a system is time consuming and unnecessary in most cases. Indeed, as the number of the details increase, verification and validation of the model becomes more difficult, increasing the error risk. Therefore the details with no significant impact on the production system, are not included in the model. Twenty different types of mattresses are manufactured by the company, each having seven different sizes. However, five most demanded types and sizes of mattresses are specified with ABC analysis (Reid and Sanders 2012) to be used in the simulation. It should be noted that the impact of other demands is neglected. Pattern of demand is not require to change production within a day. Thus it is planned that no batch change has been made during the day. Each type of selected mattress frame is

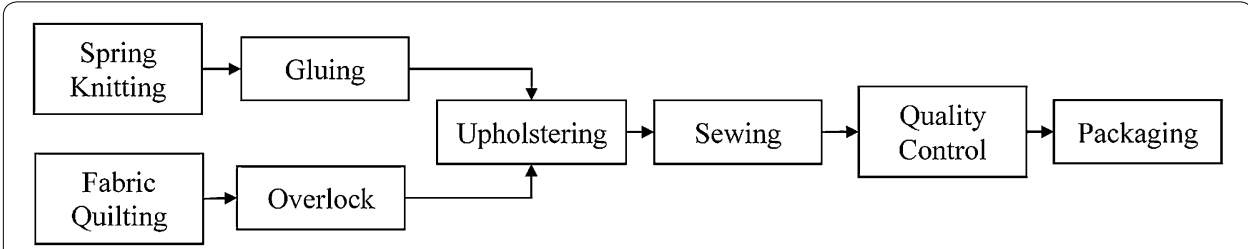

Fig. 2 Standard mattress manufacturing process 
manufactured from a different type of bonnell spring. Other specifications of these mattresses are listed in Table 2.

Production line flow is thoroughly observed and analyzed. Setup and process times of all processes are determined using the time study and statistically evaluated using "Arena input analyzer" software (Zupick et al. 2014).

In this analysis, goodness of fit (Chi square) tests are applied. Mean square error of the tests is considered to be less than $5 \%$. Results of the time study and input analysis were found too long to include in this paper so an example of these analyses are shown in Fig. 3.

After the analyses, machine setup times, current capacities of stations and changeability of capacity are given in Table 3 . The company management declared that the capacity of fabric quilting and packaging stations could not be modified, due to the high investment costs which are likely to add to the constraints already available in this problem. Also, the company can afford maximum two buffer stock areas.

Company do not want to waste time with setup times as a production strategy. In order to do that they do not frequently change manufactured product. They start with a product and continue to produce till the order finishes. After that they set-up machines and start to produce next product.

In this scope, after the capacity enhancements completed buffer stock locations are determined, if required. Besides that determining the amount of buffer stocks are out

Table 2 Specifications of mattresses

\begin{tabular}{lllll}
\hline Type & Fabric & Comfort & Overlock & Size (cm) \\
\hline A & Jacquard & Ergonomic & No & $90 \times 190$ \\
B & Jacquard & Ergonomic & No & $70 \times 180$ \\
C & Non-sweat & Ultra ergonomic & Yes & $150 \times 200$ \\
D & Non-sweat & Ultra ergonomic & Yes & $150 \times 200$ \\
E & Jacquard & Standard & No & $150 \times 200$ \\
\hline
\end{tabular}

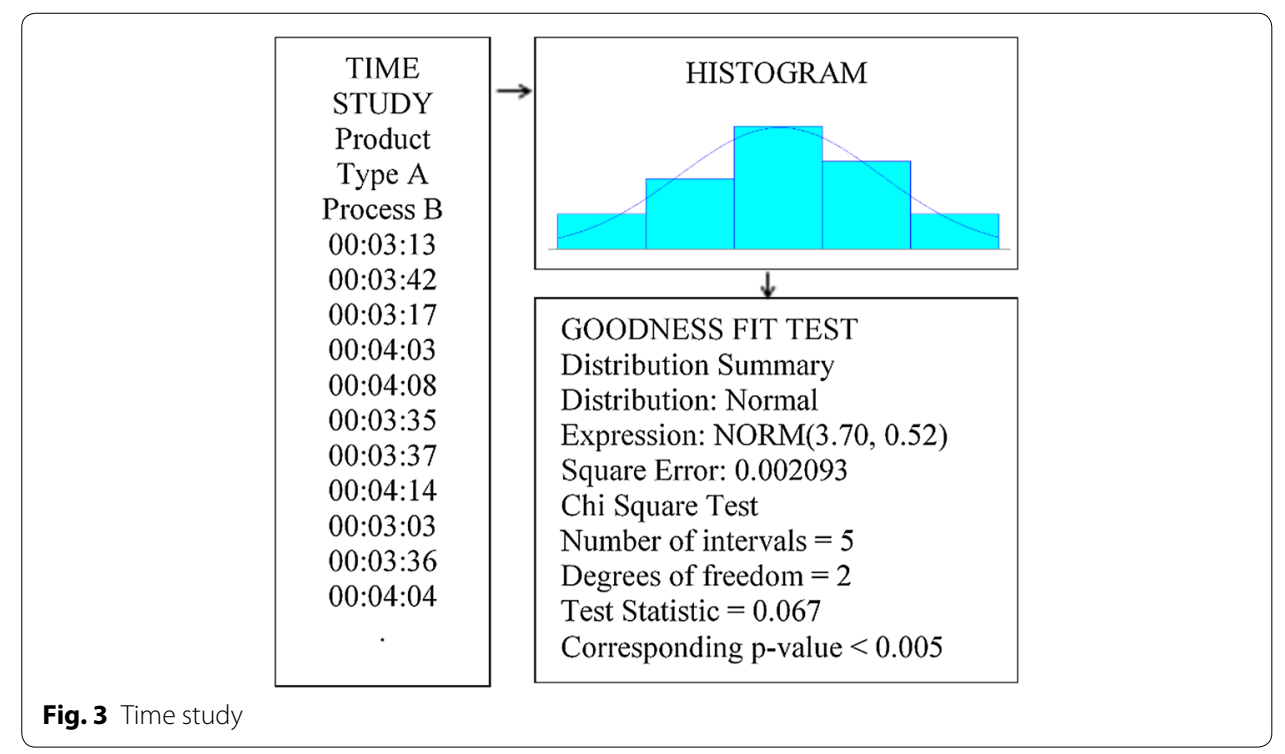


Table 3 Machines' specification

\begin{tabular}{lllll}
\hline Machine codes & Machine name & ${\text { Setup times }(\mathbf{m i n})^{\mathbf{a}}}$ & Current capacity & Modifiability of capacity \\
\hline $\mathrm{r} 1$ & Spring knitting & 15 & 2 & Yes \\
$\mathrm{r} 2$ & Glue & 15 & 2 & Yes \\
$\mathrm{r} 3$ & Fabric quilting & 10 & 1 & $\mathrm{~N} / \mathrm{A}$ \\
$\mathrm{r} 4$ & Overlock & N/A & 1 & Yes \\
$\mathrm{r} 5$ & Upholster & N/A & 1 & Yes \\
$\mathrm{r} 6$ & Sewing & 1.56 & 2 & Yes \\
$\mathrm{r} 7$ & Quality control & N/A & 2 & Yes \\
r8 & Package & 3.23 & 2 & N/A \\
\hline
\end{tabular}

N/A not applicable

a Distribution of the setup times are ignored due to high production quantities

of the scope of this study. On the other hand there are works such as Reyes et al. (2015) which have been studied the sensitivity of buffer stock amount using TOC methodology.

Processing time matrix of the stations are given in Tables 4 and 5.

\section{The theory of constraints}

In a production or service system all processes are related with its predecessor and successor if available. Each process has a limited production capacity within its constraints. In almost all cases there is only one process that limits or restricts the performance of entire system (Chapman 2005). Theory of constraints is based on the premise that the rate of goal achievement by a goal oriented system is limited by at least one constraint and adopts the common idiom as "a chain is no stronger than its weakest link". That is to say systems or part of systems are vulnerable because the weakest element or part

Table 4 Processing time matrix for spring knitting, gluing, fabric quilting, and overlock stations (min)

\begin{tabular}{|c|c|c|c|c|}
\hline $\begin{array}{l}\text { Product } \\
\text { name }\end{array}$ & Spring knitting & Gluing & Fabric quilting & Overlock \\
\hline Type A & unif $(4.07,6.83$, seed 1$)$ & norm $(3.70,0.52$, seed 6$)$ & $\operatorname{norm}(0.52,0.05$, seed 11$)$ & $\mathrm{N} / \mathrm{A}$ \\
\hline Type B & unif $(2.03,3.26$, seed 2$)$ & $\operatorname{norm}(2.04,0.26$, seed7) & $\operatorname{norm}(0.47,0.13$, seed 12$)$ & $\mathrm{N} / \mathrm{A}$ \\
\hline Type C & unif $(4.39,6.42$, seed 3$)$ & norm $(3.93,0.93$, seed8) & norm $(0.71,0.05$, seed 13$)$ & unif $(1.10,1.59$, seed 16$)$ \\
\hline Type D & unif $(4.39,6.42$, seed 4$)$ & norm $(3.67,0.55$, seed 9$)$ & norm $(0.71,0.05$, seed 14$)$ & unif $(1.10,1.59$, seed 17$)$ \\
\hline Type E & unif $(4.39,6.42$, seed5) & norm $(3.93,0.93$, seed 10$)$ & norm $(0.63,0.06$, seed 15$)$ & N/A \\
\hline
\end{tabular}

N/A not applicable

Table 5 Processing time matrix for covering/upholster, sewing, quality control, and packaging stations (min)

\begin{tabular}{lllll}
\hline Product name & Covering/upholster & Sewing & Quality control & Packaging \\
\hline Type A & norm $(2.43,0.25$, seed 18$)$ & unif $(2.50,5.00$, seed23) & norm $(0.82,0.35$, seed28) & 0.65 \\
Type B & norm $(1.40,0.19$, seed19) & unif $(1.75,3.34$, seed24) & norm $(0.79,0.35$, seed29) & 0.67 \\
Type C & norm $(2.34,0.15$, seed20) & unif $(3.29,5.80$, seed25) & norm $(1.46,0.18$, seed30) & 0.78 \\
Type D & norm $(2.34,0.15$, seed21) & unif $(3.29,5.80$, seed26) & norm $(1.46,0.18$, seed31) & 0.78 \\
Type E & norm $(2.34,0.15$, seed22) & unif $(3.29,5.80$, seed27) & norm $(1.46,0.18$, seed32) & 0.78 \\
\hline
\end{tabular}


can always damage or break them or at least adversely affect the output. In other words if there was no obstacle that prevents a system from achieving higher throughput, its throughput would be infinite which is not possible in a real-life system. Overall throughput can be increased only by increasing the flow through the constraint (Goldratt and Cox 1984).

Assuming the goal of a system has been articulated and its measurements defined, the logical thinking is based on a continuous improvement cycle with five steps (Goldratt and Cox 1992):

1. Identify the bottleneck,

2. Decide how to exploit the bottleneck,

3. Subordinate everything else in the system to the previous step,

4. Elevate the bottleneck, and.

5. Evaluate if the bottleneck has been broken, and return to the beginning

These five steps of TOC has been applied to find out bottlenecks and get information about elevating them from the production system.

\section{Simulation model}

During the stage of setting a simulation model, "progressive refinement" and "increased expansion" techniques, recommended by Law and Kelton (1991), are used and their suggestions to the modeling stage are considered. According to these suggestions, although there are established rules in some of the companies for the modelling process, there is a consensus on starting with the simple model and adding on the details when required. The model should involve only sufficient amount of details. One-to-one pairing with all components of the system is not required. This way the probability for occurrence of the errors will be minimized (Law and Kelton 1991).

Firstly, orders are defined in the system. In the second step, all machinery (sources) and their capacities within the production environment are defined. In the third step, the routes between the machines are defined. In the fourth, the rules and matrixes required for integration of assets (raw material, semi products) during the production process, were established. In the last step, the animation of overall system is prepared and synchronized with the model.

Production line is left as it is after finishing the $8 \mathrm{~h}$ of daily work and continues from there in the next working day. So reoccurring of steady state is beside the point as long as orders of that product are not completed. In other words production line is continuously produce until the orders of a product is finished. Therefore type of this system is non-terminating.

In the simulation it was assumed that;

- The machines do not malfunction

- No preventive maintenance is carried out on the machines

- There is no defective manufacturing

- All material stocks are sufficient

- A net working day is $8 \mathrm{~h}$ (after subtracting the tea and lunch breaks) 
- There is no physical obstruction within the production environment

- Initially, there is no work in process

The animation interface of simulation model, established as a result of implementation of all abovementioned steps in Arena Simulation Software, is given in Fig. 4 (Pegden et al. 1995; Rossetti 2015).

There are more than one way to eliminate a bottleneck. The foremost and easy to use one of these is the increasing the source capacity of a bottleneck. Besides that there are various methods that could eliminate a bottleneck by shifting that bottleneck to another process and help achieve output goals such as regulating break times, effective planning on production schedule of sources (using proper queue discipline), using buffer stocks, and improve production processes by R\&D studies, etc. In this context, production quantities are increased with two steps. Capacity of sources increased in the first step and buffer stocks are used in the second step to utilize dead times when a source got starve.

In each production period, the manufacturing line should be re-balanced because of the modifications in the product range. Line balancing focuses on the workers and the machine capacity. In the first step, different iterative simulation scenarios are tried to increase the daily mattress production, and the second step focuses on the types and locations of buffer stocks (after the spring knitting, fabric quilting, gluing, and overlock stations) to run the manufacturing line without a hitch. Goldratt and Coxs' (1984) bottleneck elimination algorithm embedded DES flow diagram of manufacturing model is given in Fig. 5.

This closed loop algorithm improves models in each iteration by using current simulation model. Quantity of daily production units are taken as a performance measure for algorithm. Starting with the initial model which is the current state of the firm, manufacturing simulator calculates the values and records the internal simulation performance measures database.

Algorithm records the quantity statistics of semi-finished products. In other words queue lengths of sources are calculated. According to TOC, bottleneck source has the longest queue of all sources in a production system. Thus bottleneck to work on can be identified. Simulation is re-run after making required improvements to find out the

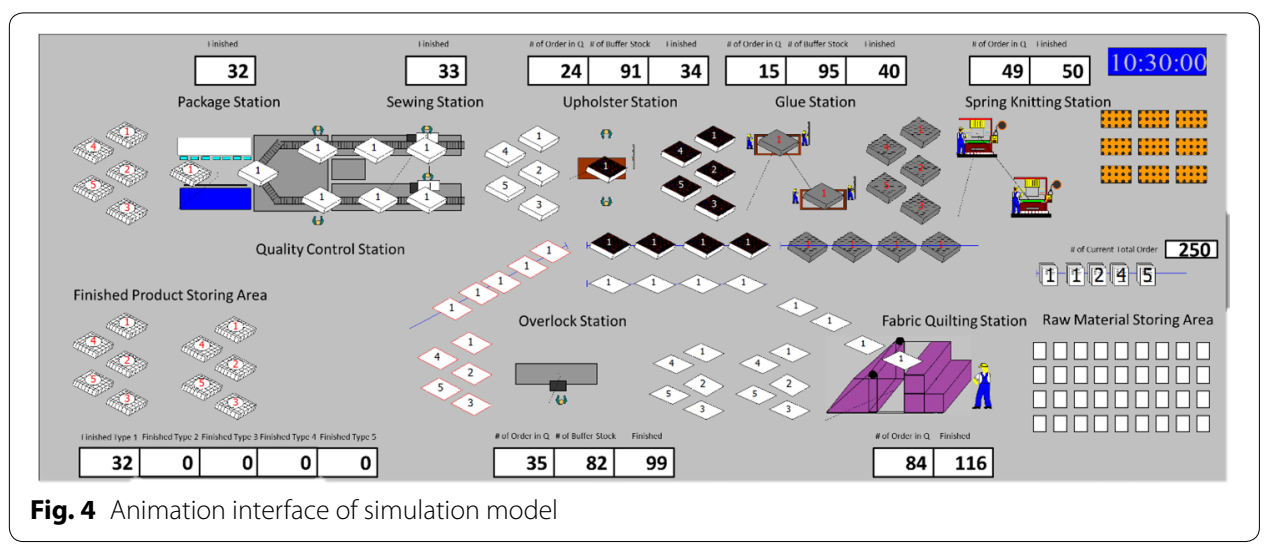




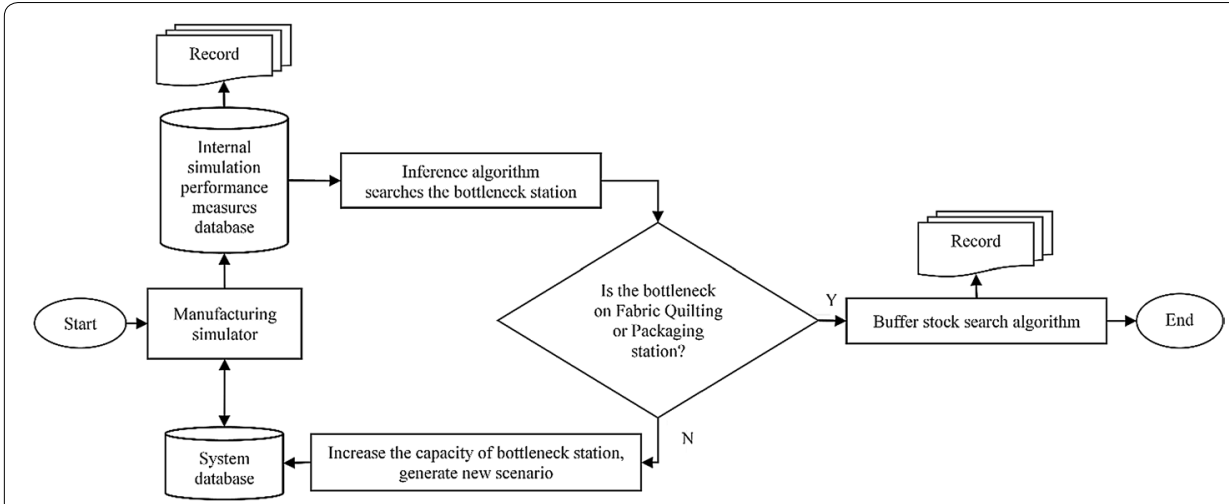

Fig. 5 Bottleneck elimination algorithm embedded DES diagram of manufacturing model

source which have the longest queue until the objective quantity achieved or a stopping criteria is met.

Inference algorithm searches for the bottleneck station from these values. There is a control stage which checks whether the bottleneck station is Fabric Quilting or Packaging stations. Algorithm increases the capacity of bottleneck station and generates a new scenario, if there are bottleneck in one of these stations. This new scenario is recorded to system database and sent to the manufacturing simulator for calculations. Algorithm try to find better scenario as long as there are bottleneck in these stations.

Otherwise, buffer stock search algorithm is executed to find appropriate buffer stocks for the stations using brute force method. It finds out all possible combinations of buffer stock locations and simulate with high quantities of buffer stocks. After that calculations are recorded and algorithm is terminated. In this case, theoretically there are 7 different buffer stock locations. Thus there are $28\left(\left(\begin{array}{l}7 \\ 1\end{array}\right)+\left(\begin{array}{l}7 \\ 2\end{array}\right)\right)$ different scenarios that can use 1 or 2 different buffer stock locations.

While evaluating the outputs of the scenarios, the point estimates for performance values (production quantities) will not be sufficient in terms of statistical evaluation. Accordingly, the decision maker will have to evaluate the confidence intervals (CI) of the performance values. A certain number of experimental results will be required for confidence interval evaluation. For this, the experiments will be replicated-with different random number series. The half-width (h) values, as a non-biased deviation measure, will be calculated for the obtained result data. The $h$ value is calculated as in Eq. 1 .

$$
h=t_{n-1,(1-a) / 2} \times \frac{s}{\sqrt{n}}
$$

In this equation; $\mathrm{t}$ shows the corresponding $\mathrm{t}$-distribution table value of test model, $\mathrm{n}$ is the sample size (number of replications), $\alpha$ is the significance level of the test (percent of confidence interval), and $s$ is the standard deviation of samples (outputs).

Increasing the number of replications will also increase the accuracy, and it will reduce the half-widths of output parameters. In this study, the half-width values are calculated so that maximum one product shows deviation, using the number of replications within the equation in the literature (Firoozi et al. 2013). In this point we took the parameter 
based on deviation of daily production quantities. It can be seen in Tables 6 and 7 that half-width values cannot be higher than +1.00 . Consequently, sufficient number of halfwidth values was reached when the number of replications was 34 . The number of replications is calculated as shown in Eq. 2.

$$
n^{*}=\left[n \times\left(\frac{h}{h^{*}}\right)^{2}\right]+1
$$

In this equation; $\mathrm{n}^{*}$ is the new number of replications to yield new required half-width $\left(h^{*}\right), \mathrm{n}$ shows the fixed initial replication to determine the number of replications (10 replications in this case), $\mathrm{h}$ is the half-width value obtained as a result of initial replication, and $\mathrm{h}^{*}$ is the maximum half-width value approved by the decision maker.

\section{Model verification and validation}

For verification of the model, Bottom-Up Testing as one of the most fundamental methods, is used (Balci 1998; Banks 1998). In this stage it was detected whether the model functions correctly using the debugging tool of the package software and detecting the systematic errors and code errors, the bugs were corrected and all lines of the model were checked. Additionally, limits of the model were pushed by excessive values and the system was deliberately forced to produce logical errors. This way the model was verified through debugging.

There is a warm-up period because of the non-terminating systems' nature. When this production line started to produce a different product, it took approximately $30 \mathrm{~min}$ to get first product. Experiments and observations shows that steady state has been reached for all products at the end of first 60 min of simulation. Consequently warm-up period has been taken as $60 \mathrm{~min}$ and simulation data of first $60 \mathrm{~min}$ is not considered in calculations to prevent objective parameters to be affected by this statistics.

According to (Conway et al. 1986) who have in-depth knowledge on simulation, adding statistical accuracy on the simulation results may be delusive, since the simulation results may hold much or less significance based on the problem type, accordingly this should be the guidance for a simulator; if you are able to see it with bare eyes, do not dwell upon it. Similarly, Yeroğlu (2001) suggested that the most important benefit of simulation is not searching for absolute answers, therefore putting great emphasis on the accuracy of the simulation results should be avoided.

The validation of the model was provided through implementation of the procedures suggested by Law and Kelton (1991). In this stage, the algorithm and the relations were studied and model animation was thoroughly observed. It was confirmed that the current case scenario is in accordance with the data received from the company. Analytical models are designed for simple fictive models and the results are compared with $t$ test. The fictive models in this study, however, are too large and complex to be represented by an analytical method. On the other hand the scenario results produced in a fictive fashion by the algorithm, are found to be within the solution space. As a result of these analyses, the model was validated. 
Table 6 Average production quantities and half-width values of iterative resource capacity simulation runnings

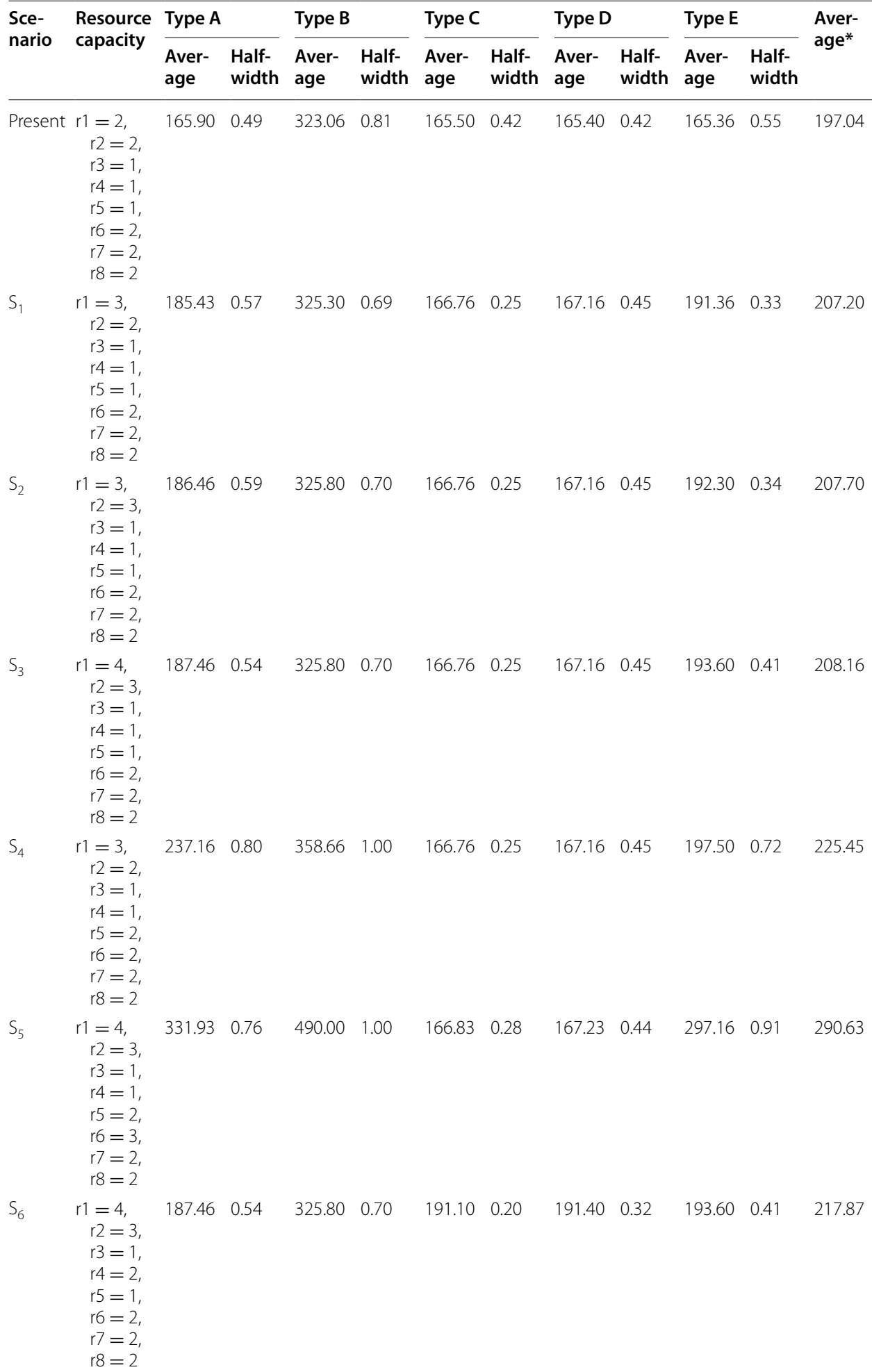


Table 6 continued

\begin{tabular}{|c|c|c|c|c|c|c|c|c|c|c|c|c|}
\hline \multirow{2}{*}{$\begin{array}{l}\text { Sce- } \\
\text { nario }\end{array}$} & \multirow{2}{*}{$\begin{array}{l}\text { Resource } \\
\text { capacity }\end{array}$} & \multicolumn{2}{|c|}{ Type A } & \multicolumn{2}{|l|}{ Type B } & \multicolumn{2}{|c|}{ Type C } & \multicolumn{2}{|c|}{ Type D } & \multicolumn{2}{|l|}{ Type E } & \multirow{2}{*}{$\begin{array}{l}\text { Aver- } \\
\text { age* }\end{array}$} \\
\hline & & $\begin{array}{l}\text { Aver- } \\
\text { age }\end{array}$ & $\begin{array}{l}\text { Half- } \\
\text { width }\end{array}$ & $\begin{array}{l}\text { Aver- } \\
\text { age }\end{array}$ & $\begin{array}{l}\text { Half- } \\
\text { width }\end{array}$ & $\begin{array}{l}\text { Aver- } \\
\text { age }\end{array}$ & $\begin{array}{l}\text { Half- } \\
\text { width }\end{array}$ & $\begin{array}{l}\text { Aver- } \\
\text { age }\end{array}$ & $\begin{array}{l}\text { Half- } \\
\text { width }\end{array}$ & $\begin{array}{l}\text { Aver- } \\
\text { age }\end{array}$ & $\begin{array}{l}\text { Half- } \\
\text { width }\end{array}$ & \\
\hline$\overline{S_{7}}$ & $\begin{array}{c}r 1=4 \\
r 2=3 \\
r 3=1 \\
r 4=2 \\
r 5=2 \\
r 6=2 \\
r 7=2 \\
r 8=2\end{array}$ & 242.40 & 0.96 & 360.46 & 1.00 & 197.90 & 0.55 & 198.03 & 0.65 & 200.10 & 0.76 & 239.78 \\
\hline $\mathrm{S}_{8}$ & $\begin{array}{c}r 1=4 \\
r 2=3 \\
r 3=1 \\
r 4=2 \\
r 5=2 \\
r 6=3 \\
r 7=2 \\
r 8=2\end{array}$ & 331.93 & 0.76 & 490.00 & 1.00 & 296.76 & 0.73 & 296.76 & 0.90 & 297.16 & 0.91 & 342.52 \\
\hline
\end{tabular}

Table 7 Final step of iterative buffer stock policy simulation runnings (Average production quantities and half-width values)

\begin{tabular}{|c|c|c|c|c|c|c|c|c|c|c|c|c|}
\hline \multirow[t]{2}{*}{ Scenario } & \multirow{2}{*}{$\begin{array}{l}\text { Buffer } \\
\text { stock }\end{array}$} & \multicolumn{2}{|l|}{ Type A } & \multicolumn{2}{|l|}{ Type B } & \multicolumn{2}{|l|}{ Type C } & \multicolumn{2}{|l|}{ Type D } & \multicolumn{2}{|l|}{ Type E } & \multirow{2}{*}{$\begin{array}{l}\text { Aver- } \\
\text { age* }\end{array}$} \\
\hline & & $\begin{array}{l}\text { Aver- } \\
\text { age }\end{array}$ & $\begin{array}{l}\text { Half- } \\
\text { width }\end{array}$ & $\begin{array}{l}\text { Aver- } \\
\text { age }\end{array}$ & $\begin{array}{l}\text { Half- } \\
\text { width }\end{array}$ & $\begin{array}{l}\text { Aver- } \\
\text { age }\end{array}$ & $\begin{array}{l}\text { Half- } \\
\text { width }\end{array}$ & $\begin{array}{l}\text { Aver- } \\
\text { age }\end{array}$ & $\begin{array}{l}\text { Half- } \\
\text { width }\end{array}$ & $\begin{array}{l}\text { Aver- } \\
\text { age }\end{array}$ & $\begin{array}{l}\text { Half- } \\
\text { width }\end{array}$ & \\
\hline $\mathrm{S}_{9}$ & $\begin{array}{l}\mathrm{S}_{8}+\text { After } \\
\text { fabric } \\
\text { quilting } \\
\text { and } \\
\text { Gluing }\end{array}$ & 375.53 & 0.95 & 556.80 & 1.00 & 310.63 & 0.83 & 310.16 & 0.93 & 309.66 & 0.90 & 372.56 \\
\hline
\end{tabular}

\section{Results and conclusion}

Heuristic based iterative method is utilized to improve the balance and efficiency of production line through increasing the production capacities of the stations.

Evaluation of the simulation results shows that the current bottleneck in the manufacturing line is Spring Knitting station. With a one unit increase in the capacity of Spring Knitting station, the daily manufacturing output increases and the resulting bottleneck switches to the Gluing station. Fabric Quilting station is found to be the bottleneck according to the results of the eighth iteration.

An analysis of the $\mathrm{S}_{8}$ results indicates that some of the resources suffer from a systematical material shortage. Since the capacity of this station cannot be increased due to the company's constraints, after this point, this issue will be addressed by deployment of buffer stock in front of the stations, instead of increasing the capacity. Heuristic based iterative algorithm detects all possible buffer stock regions and deploys sufficient amounts of semi products in these points. The algorithm is terminated as the buffer stock position/positions with the highest outputs, are detected.

$\mathrm{S}_{0}$ represents the current situation of spring mattress manufacturing department. $S_{i}$ represents the i.th scenario of simulation study. At the last column of these tables, 
average productions are calculated through averaging five kind of spring mattress productions.

Average production output has increased from 197 (current situation) to 342 units a day (73.6 \% improvement), only by enhancements in resource capacities using the last scenario $\left(\mathrm{S}_{8}\right)$, which has the 4, 3, 1, 2, 2, 3, 2 and 2 resource capacity for Spring Knitting, Gluing, Fabric quilting, Overlock, Upholster, Sewing, Quality control and Packaging stations, respectively, as shown in Table 6. Also, in terms of various buffer stocks, final result of production quantities with half-width values are given in Table 7.

At the end of the algorithm, the ideal solution is found in scenario $\mathrm{S}_{9}$. According to this scenario buffer stock must be located after Fabric quilting and Gluing stations. Other scenarios are not given to present paper appropriately.

As a result, the amount of average production reached 372 units ( $88.8 \%$ improvement) by increasing the capacity near $46 \%$ with 2 buffer stocks.

The current situation, modifications on capacity suggested after the optimization and the final situation are summarized in Table 8. Also the selected scenarios and their daily production results are illustrated in Fig. 6.

In the beginning there are no buffer stock in the factory. Locations in which buffer stocks were to be placed determined with this study. Buffer stock quantities are determined very high to prevent them to become a constraint as designed in model. According to the results, averagely 30 more products are manufactured by means of buffer stocks. This numbers are naturally fluctuate a little in each replication. In practice, the whole production line shall complete the buffer stock semi products consumed within 1 day for meeting the production targets. To meet this target it will be sufficient to make overtime work only in Spring Knitting, Gluing and Fabric quilting stations. These buffer stocks are allocated as the maximum amount of stock that a machine can process in a working day. Determining the optimum size of buffer stock is out of this study's scope.

Importance and weight of these products are not given because of the data privacy policy of the company. In the light of this information focal point is to find the most balanced production system with the companies' research team. Fluctuations in product demands are natural as this situation is anticipated. Philosophy of "efficiently producing the products with the help of TOC algorithm and simulation" is main theme of this study. In this context, changes in inputs will affect the results of this study, but the philosophy will always remain as it is.

Table 8 Summary of machine capacities

\begin{tabular}{lllll}
\hline Machine codes & Machine name & Current capacity & Change & Final capacity \\
\hline$r 1$ & Spring knitting & 2 & +2 & 4 \\
$r 2$ & Gluing & 2 & +1 & 3 \\
$r 3$ & Fabric quilting & 1 & N/A & 1 \\
$r 4$ & Overlock & 1 & +1 & 2 \\
$r 5$ & 1 & +1 & 2 \\
$r 6$ & Upholster & 2 & +1 & 3 \\
$r 7$ & Sewing & 2 & - & 2 \\
$r 8$ & Quality control & 2 & N/A & 2 \\
\hline
\end{tabular}

N/A not applicable 


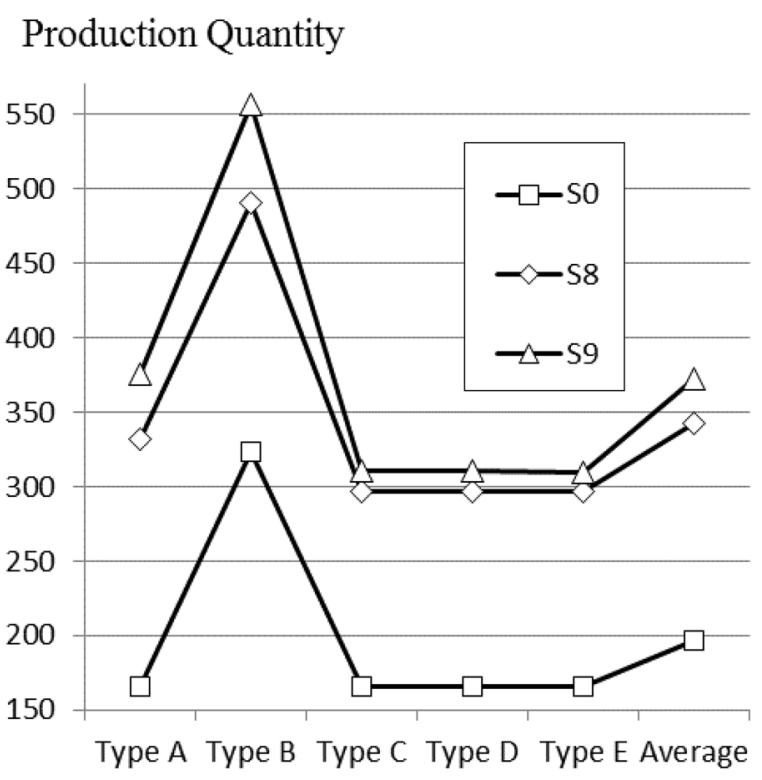

Fig. 6 Comparison of production results of selected scenarios

Although TOC has been in literature nearly 20 years some researchers supported and some are ignore it. One of the reason is that TOC is not based on serious mathematics. Therefore TOC is not widely used in different areas as many as an "artificial neural networks" for example. How TOC can be applied a different area is showed in this study. The developed solution approach can be used in any similar production and service system.

\section{Authors' contributions}

MS conceived the study idea; MS and AHK developed model. MS developed simulation and conducted evaluations. $M S, E G$, and AHK contributed to compiling the manuscript and have approved the final version. All authors read and approved the final manuscript.

\section{Acknowledgements}

The authors would like to thank Assoc. Prof. Dr. Gökalp Yıldız for his support during simulation and also, authors wish to express their thanks to Lamia G. Kasap, Merve Evcen, and Ebru Karaduman for their helpful data collection. And also, the authors would like to thank Assist. Prof. Dr. Mümtaz Ijpek for his valuable comments on this paper.

\section{Competing interests}

The authors declare that they have no competing interests.

\section{Funding}

This research is supported by Sakarya University Scientific Research Projects Coordinatorship (BAPK) with 2013-50-02-004 project number.

Received: 29 February 2016 Accepted: 28 July 2016

Published online: 08 August 2016

\section{References}

Al-Harkan I, Hariga M (2007) A simulation optimization solution to the inventory continuous review problem with lot size dependent lead time. Arab J Sci Eng 32(2):327

Amirghasemi M, Zamani R (2014) A synergetic combination of small and large neighborhood schemes in developing an effective procedure for solving the job shop scheduling problem. SpringerPlus 3:193. doi:10.1186/2193-1801-3-193

Andelkovic PM, Andelkovic A, Dasic P (2013) The theory of constraints as a basis for production process improvement model. Актуальні проблеми економіки 10:251-260 
Baesler F, Gatica J, Correa R (2015) Simulation optimisation for operating room scheduling. Int J Simul Model (IJSIMM) 14(2):215-226. doi:10.2507/IJSIMM14(2)3.287

Balbo G, Serazzi G (1997) Asymptotic analysis of multiclass closed queueing networks: multiple bottlenecks. Perform Eval 30(3):115-152

Balci O (1998) Verification, validation, and accreditation. In: Proceedings of the 30th conference on winter simulation. IEEE Computer Society Press, Washington, p 41-48. http://www.dl.acm.org/citation.cfm?id=293183

Banks J (1998) Handbook of simulation: principles, methodology, advances, applications, and practice. Wiley, New York

Boyd L, Gupta M (2004) Constraints management: what is the theory? Int J Oper Prod Manag 24(4):350-371

Chapman SN (2005) The fundamentals of production planning and control. Pearson, Upper Saddle River

Chiang S-Y, Kuo C-T, Meerkov SM (2001) C-Bottlenecks in serial production lines: identification and application. Math Prob Eng 7(6):543-578

Conway RW, Maxwell WL, Worona SL (1986) User's guide to Xcell: factory modeling system. Scientific Press, San Francisco

Firoozi Z, Tang SH, Ariafar S, Ariffin M (2013) An optimization Approach for a joint location inventory model considering quantity discount policy. Arab J Sci Eng 38(4):983-991

Goldratt EM, Cox J (1984) The goal: excellence in manufacturing. North River Press, Great Barrington

Goldratt EM, Cox J (1992) The goal: a process of ongoing improvement. North River Press, Great Barrington

Gopalakrishnan M, Skoogh A, Laroque C (2014) Simulation-based planning of maintenance activities by a shifting priority method. In: Simulation conference (WSC), 2014 Winter, 2168-2179. IEEE, New York. http://www.ieeexplore.ieee.org/ xpls/abs_all.jsp?arnumber $=7020061$

Gupta MC, Boyd LH (2008) Theory of constraints: a theory for operations management. Int J Oper Prod Manag 28(10):991-1012

Lam SSW, Zhang ZC, Oh HC, Ng YY, Wah W, Hock Ong ME, on behalf of the Cardiac Arrest Resuscitation Epidemiology (CARE) Study Group (2014) Reducing ambulance response times using discrete event simulation. Prehosp Emerg Care 18(2):207-216. doi:10.3109/10903127.2013.836266

Law AM, David Kelton W (1991) Simulation modeling and analysis, 3rd edn. McGraw-Hill, Singapore

Lawrence SR, Buss AH (1995) Economic analysis of production bottlenecks. Math Prob Eng 1(4):341-363

Leporis M, Králová Z (2010) A simulation approach to production line bottleneck analysis. In: International conference cybernetics and informatics, vol 10, Vyšná Boca, p 13

Li L, Chang Q, Ni J, Xiao G, Biller S (2007) Bottleneck detection of manufacturing systems using data driven method. In: IEEE international symposium on assembly and manufacturing (ISAM'07). IEEE, Ann Arbor, p 76-81. http://www. ieeexplore.ieee.org/xpls/abs_all.jsp?arnumber=4288452

Li L, Chang Q, Ni J, Biller S (2009) Real time production improvement through bottleneck control. Int J Prod Res 47(21):6145-6158

Mabin VJ, Balderstone SJ (2003) The performance of the theory of constraints methodology: analysis and discussion of successful TOC applications. Int J Oper Prod Manag 23(6):568-595. doi:10.1108/01443570310476636

Orouji M (2016) Theory of constraints: a state-of-art review. Accounting 2(1):45-52. doi:10.5267/j.ac.2015.12.004

Pegden CD, Sadowski RP, Shannon RE (1995) Introduction to simulation using SIMAN, 2nd edn. McGraw-Hill, Inc, USA

Puche J, Ponte B, Costas J, Pino R, Fuente D (2016) Systemic approach to supply chain management through the viable system model and the theory of constraints. Prod Plan Control 27(5):421-430. doi:10.1080/09537287.2015.1132349

Razavi B, Einafshar A, Sassani F (2015) Decision analysis model for optimal aircraft engine maintenance policies using discrete event simulation. In: Fathi M (ed) Integrated systems: innovations and applications, Springer International Publishing, Berlin, p 69-87. http://link.springer.com/chapter/10.1007/978-3-319-15898-3_5

Reid RD, Sanders NR (2012) Operations management, 5th edn. Wiley, Hoboken

Reyes J, Alvarez K, Vasquez R (2015) Dynamic buffer management for raw material supply in the footwear industry. J Ind Intell Inf 4(1):1-8. doi:10.12720/jiii.4.1

Rossetti MD (2015) Simulation modeling and arena. Wiley, New York

Sari M, Erkayman B, Gundogar E, Duman E (2013) A debottlenecking study for production line in mattress manufacturing. In: INFORMS conference on business analytics and operations research. INFORMS, Texas

Sari M, Hulusi Kokcam A, Gundogar E (2014) Simulation based optimization on mattress manufacturing line. In: International conference on computational and experimental science and engineering (ICCESEN 2014). ICCESEN, Antalya

Sarı M, Gundogar E, Ipek M (2014) An improvement study for mattress manufacturing line with a simulation model. Model World Acad Sci Eng Technol Ind Manuf Eng 1(8):236

Scholz-Reiter B, Windt K, Liu H (2011) Modelling dynamic bottlenecks in production networks. Int J Comput Integr Manuf 24(5):391-404

Üstün S (2005) Analysis by simulation of bottleneck problems in a job shop production system. MSc Thesis, Institute of Science, Karadeniz Technical University, Trabzon

Van Delft C, Dallery Y, Youssef KH, et al (2008) Priority allocation decisions in large scale MTO/MTS-multi-product manufacturing systems: technical report. https://www.ideas.repec.org/p/hal/wpaper/hal-00578367.html

Volling T, Spengler TS (2011) Modeling and simulation of order-driven planning policies in build-to-order automobile production. Int J Prod Econ 131(1):183-193

Yeroğlu C (2001) Üretim ve Servis Sistemlerinde Pratik Simülasyon Teknikleri. Atlas yayınevi, İstanbul

Zupick N, Sadowski R, Kelton WD (2014) Simulation with arena. McGraw-Hill Education, New York 